\title{
Illinois Zorbalık, Kavga ve Mağduriyet Ölçeğinin (IZKMÖ) Türkçeye Uyarlama Çalışması
}

\author{
DOI: $10.26466 / o p u s .768247$
}

\author{
*

\begin{abstract}
Mustafa Aydın* - Erkan Efilti ${ }^{* *}$ - Mustafa Diker***
* Dr. Öğrt. Üyesi,Necmettin Erbakan Üni., Ahmet Keleşoğlu Eğitim Fakültesi,Konya/Türkiye E-Posta: maydinselcuk@gmail.com ORCID: 0000-0001-8414-0008

** Doç. Dr, Necmettin Erbakan Üniversitesi, Ahmet Keleşoğlu Eğitim Fakültesi, Konya/Türkiye E-Posta: eefilti@konya.edu.tr ORCID: $\underline{0000-0003-1158-5764}$ *** Öğretmen, Altınçağ Ortaokulu, Milli Eğitim Bakanlığı, Dörtyol, Hatay/Türkiye E-Posta: dikerweb@gmail.com

ORCID: $\quad$ 0000-0002-1894-1234
\end{abstract}

\begin{abstract}
Öz
Zorbalık, günümüzde tüm dünyada eğitim öğretimin her kademesinde görülebilen ve öğrencilerin fiziksel ve ruhsal sağlığını tehdit eden oldukça ciddi bir sorun halini almıştır. Toplumsallaşmanın ilk adımlarının atıldığ̆ okullarda zorbalık ve saldırganlık gibi davranışların sıklıkla görülmesi, tüm çocukların geleceğini, psikososyal sağllğım derinden etkileyebilmektedir. Okullarda bu tür davranışların önlenebilmesi amacıyla yapılacak çalışmalarda bu davranışların çeşitli bileşenlerinin ölçülmesi önem arz etmektedir. Gerçekleştirilen bu araştırmada, Illinois Zorbalık, Kavga ve Mağduriyet Ölçeği'nin (IZKMÖ) Türk Kültürüne uyarlanması amaçlanmıştır. Illinois Zorbalık Ölçeği (IZÖ), Illinois Kavga Ölçeği (IKÖ) ve Illinois Mağduriyet Ölçeği (IMÖ) bileşenlerinden oluşan bu ölçek, Türkçe formu oluşturma aşamaları tamamlandıktan sonra 10-18 yaş aralı̆̆ındaki 637 öğrenciye uygulanmıştır. Ölçeğin üç faktörlü yapısı Doğrulayıcı Faktör Analizi (DFA) sınanmıştır. Elde edilen sonuçlar, ölçeğin iyi uyum değerlerine sahip olduğunu göstermiştir. Ölçeğin güvenirliği için, ölçeğin tamamına ve tüm alt boyutlarına ilişkin Cronbach Alfa iç tutarlılık katsayıları kontrol edilmiştir. Elde edilen sonuçlar ölçeğin tümünde 0,90; Zorbalı alt boyutu için 0,84; Mağduriyet alt boyutu için 0,83; Kavga etme alt boyutu için 0,81 şeklindedir. Ölçeğgin \%27'lik alt ve üst gruplara ilişkin $t$ - testi analizi sonuçları, ölçekteki tüm maddeler için anlamlı bir farklıllk olduğunu göstermektedir. Ayrıca ölçeğin alt boyutlarına ilişkin standart sapma, ortalama, boyutlar arası korelasyon değerleri ve güvenirlik katsayıları da hesaplanmıştır. Bu sonuçlar, IZKMMÖ' nün Türkçe ve Türk kültürüne uygun, geçerli ve güvenilir bir araç olduğunu göstermektedir.
\end{abstract}

Anahtar Kelimeler: Zorbalık, mağduriyet, kavga etme. 


\title{
The Adaptation Study of Illinois Bullying, Fighting and Victimization (IBFVS) Scale for Turkish Context
}

\begin{abstract}
Today, bullying has become a very serious problem that can be seen at all educational levels which threatens the physical and mental health of students. The frequent occurrence of bullying and aggression in schools, which is seen as the first step of socialization, can deeply affect the future and psychosocial health of all students. It is important to identify the various components of these behaviors with the studies aiming to prevent these behaviors in schools. The aim of the study is to adapt the Illinois Bullying, Fighting and Victimization Scale (IBFVS) for Turkish context. After the Turkish version was formed through required procedures, it was administered with 637 students between the ages of 10-18. Construct validity of the scale was tested via Confirmatory Factor Analysis (CFA). The obtained results showed that the scale has good fit indices. For the reliability of the scale, the Cronbach Alpha coefficients for the entire scale and all its sub-dimensions were investigated. The results obtained are 0.90 in the entire scale; 0.84 for bullying sub-dimension; 0.83 for Victimization sub-dimension; It is 0.81 for the fight sub-dimension. The results of the t-test analysis of the scale's $27 \%$ lower and $27 \%$ upper groups indicate that there is a significant difference for all items in the scale. In addition, standard deviation, mean, correlation values and reliability coefficients related to the sub-dimensions of the scale were calculated. Results show that IBFVS is a valid and reliable tool for Turkish language and Turkish culture.
\end{abstract}

Keywords: Bullying, fighting, victimization. 


\section{Giriş}

Çocukların ailede başlayan öğrenme ve sosyalleşme süreçleri, çeşitli ortamlarda akranlarıyla etkileşimleri ile gittikçe güçlenmektedir. Bu açıdan çocukların akranları ile en çok bir arada bulunduğu, vaktinin önemli bir bölümünü geçirdiği, öğrenim gördükleri okullar, sosyal ve bilişsel gelişimlerinde oldukça önemli bir yere sahiptir. Okulların, iletişim becerilerinin geliştirilmesi, olumlu davranışların kazandırılması gibi temel amaçları olmasına rağmen sık sık karşılaşılabilen olumsuz durumlar öğrenciler üzerinde ciddi etkilere sahiptir.

Çocuklarda ve gençlerde özellikle son yıllarda en çok görülen olumsuz durumlardan biri de zorbalıktır. Akran zorbalığı ile ilgili bilimsel çalışmalar 1970'li yıllarda Dan Olweus ile başlamıştır. Olweus'a (1994) göre akran zorbalığı genel olarak bir öğrencinin, zaman içinde ve tekrarlı olarak, bir ya da daha çok öğrenci tarafından olumsuz davranışlara maruz kalması olarak tanımlanmaktadır. Söz konusu olumsuz davranışlar, başka bir kişiye fiilen ve kasitlı olarak uygulanan rahatsızlık ve yaralama girişimlerini de içermektedir (Dake, Price ve Telljohann, 2003). Ayrica zorbalık, genellikle bir veya daha fazla çocuğun kendini savunamayacağ vermeyi veya rahatsız etmeyi amaçladığı bir saldırganlık biçimi olarak da tanımlanabilir (Glew, Rivara ve Freudtner, 2000).

Akran zorbalığına maruz kalan kişiler mağdur/kurban olarak adlandırılmaktadır. Zorbalık tanımlarında mağdurların yaşadığı olumsuz davranışlar genellikle bir başkasına rahatsızlık ve acı vermeye çalışmak veya kasıtlı şekilde acı çektirmek olarak öne çıkmaktadır (Pişkin, 2002). Kurbana karşı yöneltilen davranışlar sözel (alay etme, lakap takma, tehdit etme, kötü niyetli dedikodular yayma ve sataşma vb.), fiziksel (vurma, itme, saç çekme vb) veya birini arkadaş grubundan dişlama, müstehcen hareketler gibi çeşitli ilişkisel şekillerde de olabilir (Olweus, 2004).

Akran zorbalığı, okul hayatının ilk başladığı basamak olan okul öncesi eğitimi döneminden ergenlik dönemine kadar çeşitli kademelerde ve yaş gruplarında ortaya çıkabilmektedir (Uysal ve Dinçer, 2012). Arkadaşlık ilişkileri ile ilgili temellerin kazanıldığı okul öncesi dönem ve ilköğretim dönemlerinde olduğu gibi, ergenlik döneminin özelliklerinin gittikçe belirginleştiği ortaokul ve lise döneminde de akran zorbalığı önem verilmesi gereken bir durum olarak karşımıza çıkmaktadır. Çünkü bireylerin sosyal, duygusal ve 
bilişsel gelişimlerinde çok önemli bir dönem olan ergenlik dönemindeki gelişimi, bireyin hayatının her döneminde toplumla uyumlu şekilde yaşayabilmesinde büyük bir önem arz etmektedir (Kılıç, 2017). Okullarda zorbalığın sıklıkla görüldüğü ergenlik dönemi, zorbalığı gerçekleştiren, zorbalık mağduru olan ve zorbalığa tanıklık etmiş öğrencilerin yaşamlarının geri kalanında kalıcı izler bırakan bir dönemdir. Zorbalık, ergenlik dönemindeki öğrenciler için tüm ülkelerde olduğu gibi Türkiye'de de oldukça ciddi ve önemli bir sorundur (Koç, 2006).

Günümüzde zorbalık, tüm dünya ülkelerini ilgilendiren bir problem haline gelmiştir. Okullarda zorbalığın gittikçe yaygınlaşması, çocukların, gençlerin fiziksel ve ruhsal sağlığını tehdit etmektedir. Due vd. (2005), tarafından 28 ülkede 11-15 yaş arasında ve okulda eğitime devam eden ulusal temsilci örnekleri arasında zorbalığın görülme sıklığı konusunda büyük bir çalışma gerçekleştirilmiştir. Araştırmanın sonuçlarına göre genel olarak, erkek öğrencilerin \%18'i ve kız öğrencilerin \% 15'inin zorbalık davranışları gösterdikleri raporlanmıştır. Ülkeler arasında bu yüzdelik değerlerde önemli farklılıklar olmasına ve kültürel çeşitlilikler bulunmasına rağmen, sonuçlar, okul zorbalığının hem yüksek hem de düşük gelirli ülkelerde oldukça yaygın olduğunu göstermektedir.

Türkiye'de okullarda şiddet ve saldırganlık davranışlarının da artış gösterdiği ve gitgide sosyolojik bir sorun halini aldığı son yıllarda çeşitli araştırmalarda ortaya konulmuştur (Öğ̈̈lmüş, 2006; Efilti, 2008; Çubukçu ve Dönmez, 2012; Arslan, 2015). Bu davranışlara kavga etme, küfür, tehdit gibi çeşitli şekillerde rastlanılmaktadır. Ayrıca, okullarda görülen saldırganlık davranışlarıyla zorbalık davranışlarının doğrudan ilgili olduğu ifade edilmektedir (Moller, 2001). Bu durum davranışı gerçekleştiren ve mağdur olan öğrencileri etkilediği gibi, aileleri, öğretmenleri de olumsuz etkileyebilmektedir (İnan, 2005; Yavuzer, 2011). Öte yandan öğrencilerin zorbalıkla ilgili hassas/duyarlı davranma düzeyleri de zorbaca davranışlar için belirleyici olmaktadır (Dilmaç vd., 2016).

Saldırgan davranışlar çocukların toplumsallaşmaya başladığı kurumlar olan okullarda büyük rahatsızlıklara yol açmaktadır (Efilti, 2003). Okulda zorbalık ile şiddet türü olayların önlenememesi ve bu olayların sık sık tekrarlanması, okulda istenmeyen sonuçlara yol açabilir. Zorbalığın kurban üzerindeki etkileri hem kısa hem uzun vadeli olarak ortaya çımaktadır. Borg'a 
(1998) göre, zorbalığın yaygın olarak görüldüğü okullarda, öğrenciler kendilerini güvende hissetmemekte, okul yaşantılarından zevk almamakta ve bunun sonucunda okuldan soğumaktadırlar. Zorbalığın oluşturduğu kısa vadeli etkiler acı, mutsuzluk, üzüntü, aşağılık hissi, öz güven kaybı, kaygı, okuldan soğuma ve güvensizliktir. Bazı kurbanlarda karın ve baş ağrıları gibi psiko-somatik şikâyetler de gelişmektedir (Austin ve Sciarra, 2017). Ayrıca okullardaki zorbalık davranışları ile uyuşturucu kullanımı ve diğer problem davranışlarını birbirleriyle ilişkili olduğu belirtilmektedir (Ttofi vd., 2016).

Okullardaki zorbalık davranışlarını önlenmesi adına yapılacak çalışmalarda öncelikle zorbalıkla ne sıklıkta karşılaşıldığı, ne kadar yaygın olduğunun belirlenmesi oldukça önemlidir. Bu sebeple genellikle öğrenci bildirimine (self - report), öğretmen değerlendirmelerine (teacher nomination) ve akran bildirimine (peer nomination) dayalı ölçme araçları kullanılmaktadır (O'Connell, Pepler ve Craig, 1999). Öğretmen değerlendirmesi ölçekleri, öğrencilerin zorbalık davranışlarını ne sıklıkta sergiledikleri veya zorbalığa maruz kaldıklarının, davranış problemlerinin ve akranları içerisindeki yerlerinin öğretmenleri tarafından değerlendirilmesine yönelik sorular içermektedir. Ancak öğretmen değerlendirmesi ölçeklerinin eleştiri aldığı bazı noktalar vardır. Örneğin, fiziksel ve sözel zorbalık kolayca anlaşılmasına rağmen, ilişkisel zorbalık genellikle perde arkasında gerçekleştiğinden yetişkinlerin anlaması daha zor olabilmektedir. (Leff vd., 1999).

Akran bildirimi türü ölçeklerde, farklı zorbalık davranışlarına ilişkin örneklerin yer aldığı maddeler verilerek, bu davranışları en çok kimlerin sergilediği ve en çok kimlerin zorbalığa maruz kaldığı tespit edilmeye çalışılmaktadır (Schwatrz, 2000; Schwartz vd., 2002). Bu tür ölçeklerde ise arkadaş gruplarında taraflı yanıtlar verilebileceği ve fazla zaman alabileceği belirtilmektedir (Kutlu ve Aydın, 2010).

Öz bildirime dayalı araç türünde ise, Olweus tarafından geliştirilen “Olweus Zorba/Kurban Anketi" (Bully/Victim Questionnaire" yaygin kullanımı olan araçlardan biridir. Bu araç okullarda karşılaşılan zorbalık çeşitlerini, bu davranışların öğretmene ya da aileye bildirilip bildirilmediğini, ilgili davranışa müdahale edilip edilmediğini ve zorbalığın nerede gerçekleştiğini belirlemek gibi farklı durumlar için geliştirilmiştir. Ölçek, zorbalığa ilişkin tanım içermektedir. Ölçekte, zorbalık kapsamına giren ve girmeyen davranışların neler olduğuna yer verilmiştir. (Olweus D. , 1996). Bu ölçek alanda birçok araştırmada uyarlanmış ve kullanılmıştır (Salmon ve James, 1998; Ortega 
ve Lera, 2000; Wolke vd., 2000) Bu ölçek ülkemiz için de uyarlanmıştır (Dölek, 2002).

Zorbalık alanında geliştirilen ölçeklerin, sadece zorbalık davranışlarını ölçen (Crick ve Grotpeter, 1995; Austin ve Joseph, 1996; Orpinas ve Frankowski, 2001), sadece zorbalığa maruz kalma/mağduriyeti ölçen (Orpinas, 1993; Eisenberg, Neumark-Sztainer ve Perry, 2003; Mynard ve Joseph, 2000) ya da her ikisini de içeren ölçekler (Poteat ve Espelage, 2005; Tarshis ve Huffman, 2007) şeklinde geliştirildikleri görülmektedir.

Ülkemizde zorbalık ile ilgili çalışmalar incelendiğinde, veri elde etmek amacıyla geliştirilen ya da uyarlanan ölçeklerin sıkça kullanıldığı görülmüştür. Bunlara örnek olarak öğrencilerdeki zorbalık eğiliminin belirlenmesi amaciyla geliştirilen "Zorbalık Davranış Eğilim Ölçeği” ve "Akran Zorbalığı Değerlendirme Anketi" (Satan, 2006), zorbalığın duygusal, bedensel, sözel ve cinsel boyutta inceleme amaciyla uyarlanan "Şiddet-Kaba Güç Anketi" (Kepenekçi ve Çınkır, 2003), "Akran Zorbalığı Kurbanlarını Belirleme Ölçeği” (Gültekin ve Sayıl, 2005), ilköğretim birinci kademedeki öğrenciler için "Akran Zorbalığı Ölçeği: Çocuk Formu" (Pişkin ve Ayas, 2011) gösterilebilir.

$\mathrm{Bu}$ ölçeklerde genel olarak, zorbalık davranışını gerçekleştiren ve/veya zorbalığa maruz kalan öğrencilerin tespiti amaçlanmaktadır. Ölçeğin başında zorbalığın tanımının yer aldığı bu ifadelerin katılımcların cevaplarını etkileyebileceği belirtilmektedir (Neary ve Joseph, 1994). Mevcut çalışmada da, 818 yaş aralığındaki öğrencilere ilk olarak zorbalık tanımının doğrudan ya da dolaylı olarak tanıtıldığı çalışmaların aksine, davranışların öğrencilere etkisini değerlendirmelerini istemeksizin, sadece davranışların sıklığının, belirtilen davranışların son 30 günde ne sıklıkla görüldüğünün ölçülmesi hedeflenmektedir. Ayrıca ölçek, zorbalık, mağduriyet alt boyutlarının yanı sıra, şiddet ve saldırganlık ile alakalı olarak kavga etme alt boyutunu içermektedir. $\mathrm{Bu}$ sebeple bu ölçeğin akran zorbalığının tespit edilmesi ve önlenmesi çalışmalarına katkı sağlayabileceği düşünülmektedir.

Bu çalışmada Espelage ve Holt (2001) tarafından geliştirilen Illinois Zorbalık, Kavga ve Mağduriyet Ölçeği'nin (IZKMÖ) Türkçe'ye ve Türk kültürüne uyarlanarak geçerlik güvenirlik çalışmalarının yapılması sonrasında alanyazına kazandırılması amaçlanmıştır. 


\section{Yöntem}

\section{Çalışma Grubu}

Ergenlerde zorbalık davranışını araştıran bir aracın literatüre kazandırılmasını amaçlayan bu araştırma 2018-2019 öğretim yılında İç Anadolu Bölgesinde yer alan büyükşehir niteliğindeki bir ilimizde yürütülmüştür. Araştırmada veriler 10-18 yaş aralığındaki (ortaokul ve lise düzeyindeki) 637 öğrenciden elde edilmiştir. Katılımcların 355'i (\%56) kadın 282'si (\%44) erkektir. Öğrencilerin yaşına ilişkin ortalama değeri 14.88 ve medyan değeri ise $15^{\prime}$ tir.

\section{Kullanılan Ölçme Aracı}

Bu araştırmada Espelage ve Holt (2001) tarafından geliştirilen Illinois Zorbalık, Kavga ve Mağduriyet Ölçeği (IZKMÖ) ölçme aracı olarak kullanılmıştır. Bu araç, Illinois Zorbalık Ölçeği (IZÖ), Illinois Kavga Ölçeği (IKÖ) ve Illinois Mağduriyet Ölçeği (IMÖ) bileşenlerinden oluşmaktadır.

Illinois Zorbalık Ölçeği (IZÖ), 9 adet likert tipi dereceleme maddelerinden oluşmaktadır. Bu maddelerle katılımcılara son 30 gün içinde ne sıklıkla zorbalık biçimlerini (örneğin, alay etme, rahatsız etme, tehdit etme ve sosyal olarak dışlama) sergiledikleri sorulmaktadır.

Illinois Kavga Ölçeği (IKÖ), 5 adet likert tipi dereceleme maddelerinden oluşmaktadır. Bu maddelerle öğrencilere şiddet veya bedensel tehditle sonuçlanan fiziksel tartışmaları değerlendirilmektedir.

Illinois Mağduriyet Ölçeği (IMÖ) 4 adet likert tipi dereceleme maddelerinden oluşmaktadır. Bu 4 maddede bireylerin son 30 gün içinde akranlarından görebilecekleri olası mağduriyet ifadelerine yer verilmektedir. Tüm bu ölçeklerde yanıt seçenekleri "Asla", "1 veya 2 kez", "3 veya 4 kez", "5 veya 6 kez" ve "7 veya daha fazla kez" şeklindedir.

\section{Ölçeğin Uyarlanmasında Takip Edilen İşlemler}

Ölçeğin uyarlama çalışması için öncelikle ilgili makalenin sorumlu yazarı Dorothy L. Espelage ile elektronik posta yolu ile iletişime geçilmiş ve ölçeğin Türkçeye uyarlanması için gerekli izin alınmıştır. İzin alındıktan sonra uyarlama çalışmaları için çeviri işlemlerine başlanmıştır. 
Özgün dili İngilizce olan ölçek, İngilizce ve Türkçe dillerine hakim dört ayrı çevirmen tarafından birbirinden bağımsız olarak Türkçeye çevrilmiştir. Çevirmenlere çeviri işlemi öncesinde ölçeğin yapısı ve amacı hakkında gerekli bilgiler verilmiştir. Oluşturulan dört ayrı çeviri araştırmacılar ve aynı çevirmenler tarafından karşılaştırılmış, ortak bir Türkçe form haline getirilmiştir. Bu karşılaştırmada; (a) Türkçe madde ile İngilizce maddenin eşleşmiş olmasına, (b) farklı yaş gruplarındaki öğrenciler için göreli zorba/zorba olmayan kişilere uygunluğu incelenmiştir.

İlk şekli verilen Türkçe form, geri çeviri yöntemi ile iki farklı çevirmen tarafından birbirinden bağımsız olarak tekrar İngilizceye çevrilmiştir. Elde edilen çeviriler karşılaştırılmış ve gerekli görülen düzeltmeler yapılmıştır. Bu aşamada, iki psikolojik danışmandan maddelerin içerikleri ve öğrenciler tarafından uygun biçimde anlaşılabilirliği konusunda görüşleri alınarak gerekli düzeltmeler yapılmıştır. Ayrıca bir ölçme uzmanı tarafından madde formlarını ölçümlemeye uygunluğu incelenmiştir.

Oluşturulan nihai Türkçe form, farklı 3 Türkçe öğretmeni tarafından anlam bütünlüğü ve dil bilgisi yönünden kontrol edilmiş ve ölçeğin son hali hazırlanarak geçerlik ve güvenirlik çalışmalarına başlanmıştır. Tüm çeviri süreçlerinde, ölçeğin uygulanacağı yaş grubunun özellikleri göz önünde bulundurularak çalışmalar yürütülmüştür.

\section{Verilerin Analizi}

Analiz öncesinde tüm maddelere ilişkin kayıp veriler, minimum-maksimum değerler incelenerek betimsel istatistikler gözden geçirilmiştir. Ayrıca maddelere ilişkin yanıt kategorileri de yüzde olarak incelenmiştir.

Ölçeğin Türk kültürüne uyarlanmasında orijinal formda belirlenen yapıya ilişkin geçerliği sınamak amacıyla Doğrulayıcı Faktör Analizi (DFA) tekniğinden yararlanılmıştır. Bu analizin amacı her koşulda kullanılabilecek bir ölçek yapısının doğrulanmasıdır. Varyans-kovaryans matrislerine dayalı olarak yapılan tüm analizlerde modelin parametrelerini tahmin etmek için maksimum olabilirlik tahmini (MLE) kullanılmıştır (Hair ve ark. 2010).

Modelin uygunluğunu değerlendirmek için dikkate alınması gereken bazı uyum indeksleri vardır (Kline, 2010; Hair ve ark. 2010). İlk olarak, minimum uyum fonksiyonu $x^{2}$ kullanılarak belirlenmiştir. Bununla birlikte, $x 2$ 'nin örnek büyüklüğüne çok duyarlı olduğu bilindiğinden (Hu ve Bentler 1999), 
$x^{2}$ (ki-kare) değerinin serbestlik derecesine $\left(x^{2} / \mathrm{sd}\right)$ oranı dikkate alındı. Bu değerin 3'ten az olması iyi bir uyuma işaret eder. DFA modelinin geçerliğinin kanıt olarak literatürde önerildiği üzere Yaklaşık Hataların Karekökü (Root Mean Square Error of Approximation, RMSEA), Standart Ortalama Hataların Kare Kökü (Standardized Root Mean Square Residual, SRMR) ve Karşılaşttrıcı Uyum İndeksi (Comparative Fit Index, CFI) olmak üzere, dört temel uyum indeksi rapor edilmiştir (Kline, 2010).

Ölçeğin faktörleri ve tamamın ilişkin Cronbach Alfa hesaplanarak iç güvenirlik katsayılarına bakılmıştır. Ölçeğin ilgili özellikler bakımından üst ve alt \%27'lik grupları ayırması, t-testi sonuçlarına bakılarak incelenmiştir. Faktörler arasındaki ilişkilerin ortaya konması amacıyla boyular arası Pearson Momentler Çarpımı Korelasyon katsayılarına yer verilmiştir.

\section{Etik}

Ölçeğin uygulanmasında ilk izin orijinal makalenin sorumlu yazarı olan Dorothy L. Espelage'dan e-posta aracılığı ile alınmıştır. Gerçekleştirilen bu uygulama öncesi 2019 yılı Mart ayı içerisinde yetkililerden gerekli izin alınmıştır. Uygulama sürecinde potansiyel katılımcılara, katılımın gönüllü olması da dahil olmak üzere, uygulama ve amacı hakkında bilgi verilmiştir. Ölçeğin katılımcılar tarafından eksiksiz tamamlanması onam olarak kabul edilmiştir.

\section{Bulgular}

\section{Geçerliğe İlişkin Bulgular}

Espelage ve Holt (2001) tarafından geliştirilen Kavga ve Mağduriyet Ölçeği (IZKMÖ) ölçeğinin 3 boyutlu özgün yapısını test etmek için DFA işlemi gerçekleştirilmiştir. DFA sonuçlarına ilişkin model Şekil 1'de sunulmuştur.

Gerçekleştirilen DFA işleminde modelin daha iyi uyum değerleri ortaya koyması için modifikasyon değerleri incelenmiştir. Bazı maddelerin hata kovaryanslarının yüksek düzeyde ilişkili olduğu görülerek bu çiftlerden aynı gizil değişken altında yer alan maddeler arasında gözlenen yüksek hata korelasyonları modele eklenerek model tekrar test edilmiştir. Belirlenen maddelerin (m2-m9, m2-m14, m9-m16, m15-m18, m16-m17, m3-m11, m10-m12, m5-m6) hataları arasındaki korelasyonlar serbest bırakılmıştır. Nihai modelden elde edilen uyum indeksleri $\left(x^{2} / \mathrm{sd}=2.87, \mathrm{CFI}=0.96\right.$, GFI=0.94, AGFI=0.92, 
RMSEA=0.05, SRMR=0.04) 3 boyutlu bu yapının iyi (Byrne, 1998; Hu \& Bentler, 1999; Jöreskog \& Sörbom, 1993) uyum değerlerine sahip olduğunu göstermektedir. Ölçekteki maddelerin faktör yük değerleri incelendiğinde 0.38 ile 0.76 arasında bu değerlerin değiştiği ve tüm yük değerleri istatistiksel olarak anlamlı olduğu görülmüştür $(\mathrm{p}<0.001)$.

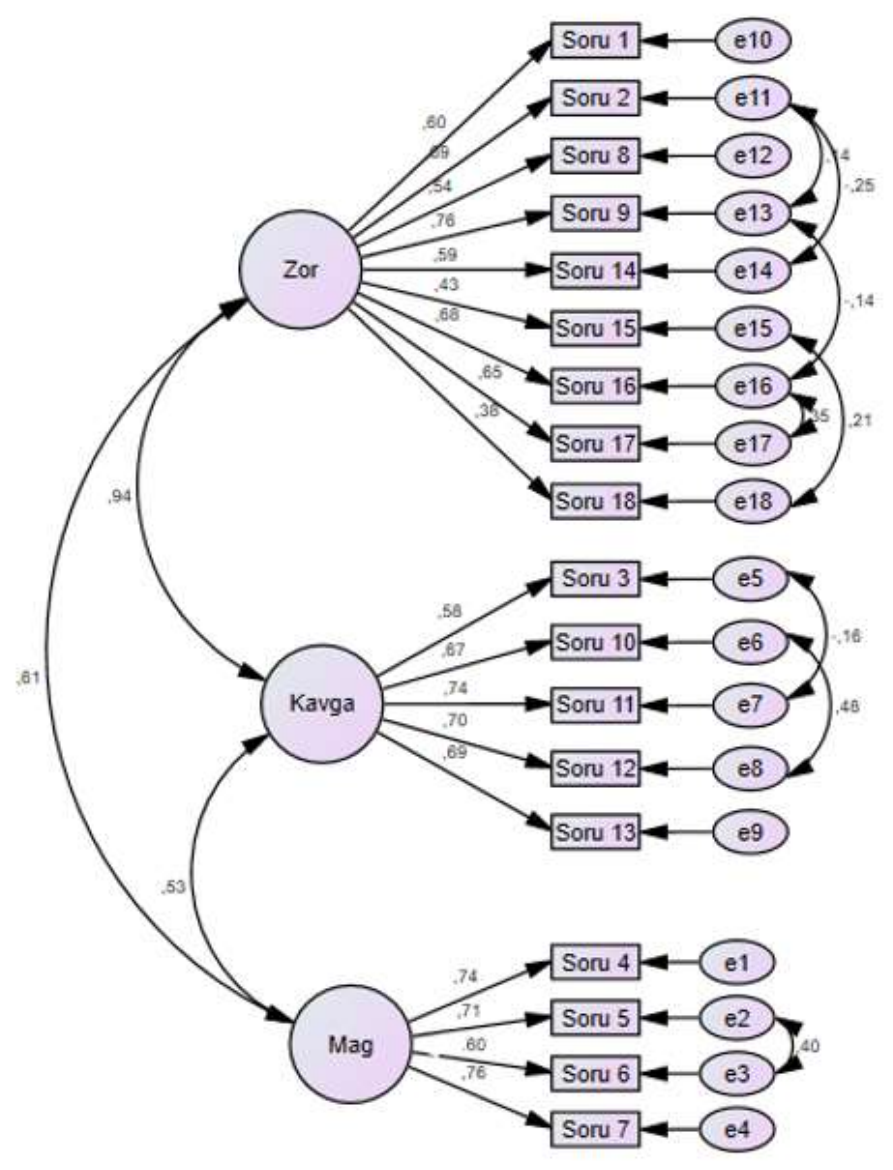

Şekil 1. Üç Faktörlü Modele İlişkin DFA Sonuçlan 


\section{Güvenirliğe İlişkin Bulgular}

IZKMÖ'nün güvenirliğini belirlemek için ölçekte yer alan her bir boyuta ilişkin ve ölçeğin tamamına ilişkin Cronbach alfa değerleri hesaplanmıştır. Ayrıca ölçek maddelerinin bireyleri ne derece ayırt ettiği alt ve üst \%27'lik dilimlerde yer alan öğrencilerin madde ortalamalarının farkı ile incelenmiştir.

Ölçeğin üst \%27 ve alt \%27'lik gruplara ilişkin ayırt ediciliği t-testi ile analiz edilmiştir. Analiz sonuçları farklı üç boyutta yer alan tüm maddeler için anlamlı bir farkı göstermektedir $(\mathrm{p}<0.001)$. Bu durum ölçeğin üst ve alt gruplarda ayırt ediciliğinin bulunduğunu göstermektedir.

Tablo 1. IZKMÖ'ye İlişkin Üst \%27 ve Alt \%27 Puanları Arasındaki t testi Sonuçlan

\begin{tabular}{|c|c|c|c|c|c|c|c|c|}
\hline \multicolumn{3}{|l|}{ Zorbalık } & \multicolumn{3}{|c|}{ Kavga Etme } & \multicolumn{3}{|c|}{ Mağduriyet } \\
\hline $\begin{array}{l}\text { Madde } \\
\text { No }\end{array}$ & $\begin{array}{l}t \\
\text { (Üst\%27 } \\
\text { Alt \%27) }\end{array}$ & - & $\begin{array}{l}\text { Madde } \\
\text { No }\end{array}$ & $\begin{array}{l}t \\
\text { (Üst \%27 } \\
\text { Alt \%27) }\end{array}$ & - & $\begin{array}{l}\text { Madde } \\
\text { No }\end{array}$ & $\begin{array}{l}t \\
\text { (Üst\%27 } \\
\text { Alt \%27) }\end{array}$ & - \\
\hline Soru 1 & 10.16 & $* *$ & Soru 3 & 11.16 & ** & Soru 4 & 24.64 & ** \\
\hline Soru 2 & 11.80 & $* *$ & Soru 10 & 15.29 & ** & Soru 5 & 20.91 & ** \\
\hline Soru 8 & 9.27 & $* *$ & Soru 11 & 10.10 & $* *$ & Soru 6 & 22.31 & ** \\
\hline Soru 14 & 15.42 & $* *$ & Soru 12 & 17.18 & ** & Soru 7 & 16.72 & $* *$ \\
\hline Soru 15 & 7.97 & $* *$ & Soru 13 & 25.83 & ** & & & \\
\hline Soru 16 & 11.81 & $* *$ & & & & & & \\
\hline Soru 17 & 11.03 & $* *$ & & & & & & \\
\hline Soru 18 & 7.863 & $* *$ & & & & & & \\
\hline${ }^{* *} \mathrm{p}<0.001$ & & & & & & & & \\
\hline
\end{tabular}

Ölçeğin tümüne ilişkin hesaplanan Cronbach Alfa güvenirlik katsayısı 0.90 olarak bulunmuştur. Zorbalık, Kavga Etme ve Mağduriyet boyutlarına ilişkin hesaplanan güvenirlik katsayıları ise sırasıyla $0.84,0.81$ ve 0.83 olarak hesaplanmıştır.

Tablo 2. IZKMÖ'nün Boyutlarna İlişkin Ortalama, Standart Sapma, Boyutlar Arası Korelasyon Değerleri ve Güvenirlik Katsayıları

\begin{tabular}{llllll}
\hline & $\bar{X}$ & SS. & Zorbalık & Mağduriyet & Cronbach Alfa \\
\hline Zorbalık & 12.52 & 5.15 & - & & 0.84 \\
Mağduriyet & 7.61 & 4.11 & $0.50^{* *}$ & - & 0.81 \\
Kavga & 8.10 & 3.99 & $0.74^{* *}$ & $0.75^{* *}$ & 0.83 \\
\hline
\end{tabular}

Ölçeğin boyutlarına ilişkin standart sapma ve aritmetik ortalama değerleri de yukarıdaki tabloda sunulmuştur. Tabloda ayrıca ölçeğin boyutları arasındaki korelasyon değerlerine de yer verilmiştir. Ölçeğin boyutları arasında pozitif yönlü yüksek korelasyon değerleri olduğu görülmüştür. 


\section{Tartışma ve Sonuç}

Bu araştırma, İllinois Zorbalık, Kavga ve Mağduriyet Ölçeği'nin (IZZKMÖ) Türkçe' ye uyarlanması ve ölçeğin geçerlik ve güvenirlik analizlerinin yapılması amacıyla gerçekleştirilmiştir. Ölçeğin yapı geçerliğinin sınanması amacıyla DFA uygulanmıştır. Ölçeğin bazı maddelerinin hata kovaryansları yüksek düzeyde ilişkili olduğu görülmüştür. Bu çiftlerden aynı gizil değişken altında yer alan maddeler arasında gözlenen yüksek hata korelasyonları modele eklenmiş ve model tekrar test edilmiştir. Analizin tekrarından elde edilen sonuçlarda tüm uyum değerleri incelendiğinde, oluşturulan Türkçe formdaki 3 boyutlu bu yapının özgün yapı ile iyi uyum değerlerine sahip ve tutarlı olduğu görülmüştür.

Ölçeğin güvenirliğinin sınanması amacıyla ölçeğin tamamına ve ölçeğin tüm alt boyutlarına ilişkin Cronbach Alfa iç tutarlılık katsayıları hesaplanmıştır. Elde edilen sonuçlar ölçeğin tümünde 0.90; Zorbalık alt boyutu için 0.84; Mağduriyet alt boyutu için 0.83; Kavga etme alt boyutu için 0.81'dir. Bu iç tutarlılık katsayılarının, orijinal ölçeğin geliştirilmesinde ve kullanıldığı diğer çalışmalarda elde edilen iç tutarlık katsayıları ile uyumlu olduğu söylenebilir. Ölçeğin uyarlandığg İran ve Pakistan'daki çalışmalarda cronbach alfa değeri Türkçe uyarlama çalışmasına göre daha düşük sonuçlar vermiştir (Balootbangan ve Talepasand, 2015; Shujja ve Atta, 2011). Ölçeğin \%27'lik alt ve üst gruplara ilişkin t- testi analizi sonuçları, ölçekteki tüm maddeler için anlamlı bir farklılık olduğunu göstermektedir ( $\mathrm{p}<0.001)$. Buna göre, ölçeğin maddelerinin ayırt edici oldukları söylenebilir. Ayrıca ölçeğin alt boyutlarına ilişkin standart sapma, ortalama, boyutlar arası korelasyon değerleri ve güvenirlik katsayıları da hesaplanmıştır ve ölçeğin alt boyutları 0.50 ile 0.75 arasında değişen yüksek korelasyon değerleri olduğu tespit edilmiştir. Bu değerler, ölçeğin özgün formunun geliştirilme çalışmasında ve kullanıldığı diğer başka araştırmalarda elde edilen değerlerle benzerlik göstermektedir (Espelage ve Holt, 2001; Espelage vd., 2014; Ahmed vd., 2018). Bu değerler aynı zamanda ölçeğin uyarlandığı diğer çalışmalarla da benzerlik göstermektedir (Balootbangan ve Talepasand, 2015; Shujja ve Atta, 2011).

Sonuç olarak, Türkçe' ye uyarlama çalışması yapılan IZKMÖ'nün özgün formunda olduğu gibi üç alt boyuttan oluştuğu ve bu alt boyutların iyi uyum 
sergilediği, ölçeğin maddelerinin ayırt edici olduğu, ölçeğin iç tutarlılık katsayılarının alanyazın için makul seviyede olduğu anlaşılmıştır. Türkçe literatüre bakıldığında (Dölek, 2002; Kutlu ve Aydın, 2010 vb.) uyarlaması yapılan bu ölçeğin alandaki ölçeklerde görülen zorbalık ve mağduriyet bileşenlerine ek olarak kavga etme boyutunu da içeriyor olması önemli bir katkı olarak görülmektedir. Ölçeğin bu bileşenlerle birlikte ilgili davranışlar arasındaki ilişkilerin açıklanmasında daha güçlü bir çerçeve sunduğu görülmektedir. Buradan haliyle, İZKMÖ'nün okullarımızdaki 10-18 yaş aralığındaki öğrencilerde zorbalık davranışlarının son 30 günde ne sıklıkta görüldüğünün tespit edilmesinde geçerli ve güvenilir bir araç olduğu söylenebilir. 


\title{
EXTENDED ABSTRACT
}

\section{The Adaptation Study of Illinois Bullying, Fighting and Victimization (IBFVS) Scale for Turkish Context}

\author{
Mustafa Aydın - Erkan Efilti - Mustafa Diker \\ Necmettin Erbakan University-Milli Eğitim Bakanlığı
}

The process of learning and socializing that starts in the family in children is getting stronger by communicating with peers in various environments. Schools are one of the places where children are mostly together with their peers. For this reason, negative experiences in schools have very serious effects on children's development. One of the most common negative situations in children and young people, especially in recent years, is bullying. Today, bullying has become a problem that concerns their country all over the world. Turkey has shown an increase in violence and aggressive behaviors in our schools and increasingly in recent years as the state takes a sociological problem is noted in various studies. It is important to measure the various components of these behaviors in studies to prevent such behaviors in schools. The aim of the study is to adapt the Illinois Bullying, Fighting and Victimization Scale (IBFVS) for Turkish context.

In this research, Illinois Bullying, Fighting and Victimization Scale (IBFVS) developed by Espelage and Holt (2001) was used as a measurement tool. This tool consists of the Illinois Bullying Scale (IBS), Illinois Fighting Scale (IFS) and the Illinois Victimization Scale (IFS). These components consist of likert type items. After the Turkish version was formed through required procedures, it was administered with 637 students between the ages of 10-18. The average age of students is 14.88 and the median is 15 . The $56 \%$ of the students were female $(n=355)$ and $44 \%$ of the students were male $(n=282)$. Construct validity of the scale was tested via Confirmatory Factor Analysis (CFA). The obtained results showed that the scale has good fit indices. For the reliability of the scale, the Cronbach Alpha coefficients for the entire scale and all its subdimensions were investigated. The results obtained are 0.90 in the entire scale; 0.84 for bullying sub-dimension; 0.83 for Victimization sub-dimension; It is 0.81 for the fight sub-dimension. 
It was observed that some items of the scale were highly correlated with error co-variances. High error correlations observed between the items under the same latent variable of these pairs were added to the model and the model was tested again. When the factor load values of the items in the scale were examined, it was seen that these values changed between 0.38 and 0.76 and all load values were statistically significant $(p<0.001)$.

To determine the reliability of IBFVS, Cronbach alpha values were calculated for each dimension in the scale and for the entire scale. In addition, the level of discriminating individuals of the scale items was examined with a significant difference between students in the lower and upper $27 \%$. The discrimination of the scale for the upper $27 \%$ and lower $27 \%$ groups was analyzed with the $t$-test. The results of the analysis show a significant difference in all items in three different dimensions ( $\mathrm{p}<0.001)$. The Cronbach Alpha reliability coefficient calculated for the entire scale was calculated to be 0.90 . The reliability coefficients calculated for bullying, fighting and victimization dimensions were calculated as $0.84,0.81$ and 0.83 , respectively. In addition, standard deviation and arithmetic mean values related to the dimensions of the scale were examined.

Validity was tested with DFA in this study, which was conducted to adapt the Illinois Bullying, Fighting and Victimization Scale (IBFVS) to Turkish. Results show that IBFVS is a valid and reliable tool for Turkish language and Turkish culture.

In order to test the IBFVS reliability of the scale, Cronbach Alfa internal consistency coefficients were calculated for the entire scale and all sub-dimensions of the scale. The results obtained are 0.90 in the entire scale; 0.84 for bullying sub-dimension; 0.83 for Victimization sub-dimension; It is 0.81 for the fighting dimension. It can be said that these internal consistency coefficients are compatible with the internal consistency coefficients obtained in the development of the original scale and other studies. In addition, standard deviation, mean, interdimensional correlation values and reliability coefficients for the sub-dimensions of the scale were calculated and the sub-dimensions of the scale were found to have high correlation values ranging from 0.50 to 0.75 .

As a result, IBFVS, which is adapted to Turkish, consists of three sub-dimensions, as in its original form, and these sub-dimensions are well-matched, the items of the scale are distinctive, the internal consistency coefficients of 
the scale are reasonable and there are high correlation values among the subdimensions of the scale. It understood. From this point of view, it can be said that IZKMÖ is a valid and reliable tool in determining how often bullying behaviors have been seen in students aged 10-18 in our schools in the last 30 days.

\section{Kaynakça / References}

Ahmed, A., Moore, T. M., Lewis, J., Butler, L., Benton, T. D., ve Boyd, R. C. (2018). Psychometric properties of bully, fighting, and victimization scales among clinically referred youth. Journal of Aggression, Maltreatment \& Trauma, 27(10), 11101124.

Arslan, Y. (2015). Okullarda yaşanan şiddet olaylarının düzey ve dinamiklerini anlamak: Batman Merkez örneği/Türkiye. Manas Sosyal Araştırmalar Dergisi, 4(5), 1-17.

Austin, S., ve Joseph, S. (1996). Assessment of bully/victim problems in 8-11 year-olds. British Journal of Educational Psychology, 66, 447-456.

Austin, V. L., \& Sciarra, D. T. (2017). Çocukve ergenlerde duygusal ve davranışsal bozukluklar (1. Basımdan Çeviri b.). (D. M.Özekes, Çev.) Ankara: Nobel Akademik Yayıncllik.

Balootbangan, A., ve Talepasand, S. (2015). Validation of the Illinois bullying scale in primary school students of Semnan, Iran. Journal of Fundamentals of Mental Health, 17(4), 178-85.

Borg, M. (1998). The emotional reactions of school bullies and their victims. Educational Psychology, 18, 433-444.

Byrne, B. M. (1998). Structural equation modeling with LISREL. Prelis, and Simplis, 196199.

Crick, N. R., ve Grotpeter, J. K. (1995). Relational aggression, gender, and social psychological adjustment. Child Development, 66, 710-722.

Çubukçu, Z., ve Dönmez, A. (2012). İköğretim okullarında görev yapan öğretmenlerin okuldaki şiddet üzerine görüssleri. Elektronik Sosyal Bilimler Dergisi, 11(40), 29108.

Dake, J. A., Price, J. H., ve Telljohann, S. K. (2003). The nature and extent of bullying at school. Journal of School Health, 73(5), 173-180.

Dölek, N. (2002). Öğrencilerde zorbaca davranışlarm araştırlması ve bir önleyici program modeli., Yayınlanmamış Doktora Tezi): Marmara Üniversitesi Eğitim Bilimleri Enstitüsü. İstanbul. 
Due, P., Holstein, B. E., Lynch, J., Diderichsen, F., Gabhain, S. N., Scheidt, P., ve Currie, C. (2005). Bullying and symptoms among school-aged children: international comparative cross sectional study in 28 countries. European journal of public health, 15(2), 128-132.

Dilmaç, B., Yurt, E., Aydın, M., ve Kaşarcı, İ. (2016). Predictive relationship between humane values of adolescents cyberbullying and cyberbullying sensibility. Electronic Journal of Research in Educational Psychology, 14(1), 3-22.

Efilti, E. (2003). Çocuklar saldırganlığı nasıl öğrenir. (Ed. Sünbül A.M), Eğitime Yeni Bakışla 2. içinde (s.189-198). Konya: Mikro Yayınları.

Efilti, E. (2008). Orta öğretim kurumlarında okuyan öğrencilerin saldırganlık ve denetim odağı'nın karşılaştırmalı olarak incelenmesi. S.Ü. Sosyal Bilimler Enstitüsü Dergisi (19), 213-230.

Eisenberg, M. E., Neumark-Sztainer, D., ve Perry, C. L. (2003). Peer harassment, school connectedness, and academic achievement. Journal of School Health, 73, 311-316.

Espelage, D. L., ve Holt, M. K. (2001). Bullying and victimization during early adolescence. Journal of Emotional Abuse, 2(2-3), 123-142.

Espelage, D. L., Polanin, J. R., ve Low, S. K. (2014). Teacher and staff perceptions of school environment as predictors of student aggression, victimization, and willingness to intervene in bullying situations. School Psychology Quarterly, 29(3), 287-305.

Glew, G., Rivara, F., ve Freudtner, C. (2000). Bullying: Children hurting children. Pediatrics in Review, 21(6), 183-190.

Gültekin, Z., ve Sayıl, M. (2005). Akran zorbalığını belirleme ölçeği geliştirme çalışması. Türk Psikoloji Yazıları, 8(15), 121-138.

Hu, L. T., ve Bentler, P. M. (1999). Cutoff criteria for fit indexes in covariance structure analysis: Conventional criteria versus new alternatives. Structural equation modeling: a multidisciplinary journal, 6(1), 1-55.

İnan, H. Z. (2005). Okullarda çocuklar arası zorbalık. M.Ü. Atatürk Eğitim Fakültesi Eğitim Bilimleri Dergisi(22), 161-170.

Jöreskog, K. G., ve Sörbom, D. (1993). LISREL 8: Structural equation modeling with the SIMPLIS command language. Scientific Software International.

Kepenekçi, Y., ve Çınkır, D. (2003). Öğrenciler arası zorbalık. Kuram ve Uygulamada Ĕ̆gitim Yönetimi, 34(34), 236-253.

Kılıç, N. (2017). Ortaokul 6, 7 ve 8. sınıf öğrencilerinin zorbalık düzeylerinin yordanması (Konya ili Cihanbeyli ilçesi örneği). Journal of Educational Reflections, 1(2), 37-58.

Kline, R. B. (2010). Principles and practice of structural equation modeling. Guilford publications. 
Koç, Z. (2006). Lise öğrencilerinin zorbalık düzeylerinin yordanması. Ankara, Yayınlanmış Doktora Tezi: Gazi Üniversitesi Eğitim Bilimleri Enstitüsü.

Kutlu, F., ve Aydın, G. (2010). Akran zorbalığı ölçek geliştirme ön çalışması: Kendini bildirim formu. Türk Psikoloji Yazılar, 13(25), 1-12.

Leff, S. S., Patterson, C. J., Kupersmith, J. B., ve Power, T. J. (1999). Factors infl uencing teacher identifi cation of peer bullies and victim. School Psychology Review, 28(3), 505-517.

Moller, T. (2001). Youth aggression and violence: A psychological approach. London: Lawrence Erlbaum Associates.

Mynard, H., ve Joseph, S. (2000). Development of the Multidimensional Peer-Victimization Scale. Aggressive Behavior, 26, 169-178.

Neary, A., ve Joseph, S. (1994). Peer victimization and its relationship to self-concept and depression among school girls. Personality and Individual Differences, 16(1), 183186.

O'Connell, P., Pepler, D., ve Craig, W. (1999). Peer involvement in bullying; Insights and challenges for intervention. Journal of Adolescence, 22, 437-452.

Olweus, D. (1994). Bullying at school: basic facts and effects of a school based intervention program. Journal of child psychology and psychiatry, 35(7), 1171-1190.

Olweus, D. (1996). The Olweus bully/victim questionnaire. Mimeo, HEMIL, University of Bergen, N-5015 Bergen Norwey.

Olweus, D. (2004). The Olweus Bullying Prevention Programme: Design and implementation issues and a new national initiative in Norway. Bullying in schools: How successful can interventions be, 13-36.

Orpinas, P. (1993). Skills training and social influences for violence prevention in middle schools: A curriculum evaluation. Doctoral dissertation, University of Texas-Houston, School of Public Health. Dissertation Abstracts International, 94-01778.

Orpinas, P., ve Frankowski, R. (2001). The aggression scale: A self-report measure of aggressive behavior for young adolescents. Journal of Early Adolesence, 21, 5067.

Ortega, R., ve Lera, M. (2000). The Seville Anti-bullying in School Project. Aggressive Behavior, 26, 113-123.

Öğülmüş, S. (2006). Okullarda şiddet ve alınabilecek önlemler. Eğitime Bakış Dergisi, 2(7), $16-24$.

Pişkin, M. (2002). Okul zorbalığı: Tanımı, türleri, ilişkili olduğu faktörler ve alınabilecek önlemler. Kuram ve Uygulamada Ĕ̆itim Bilimleri, 2(2), 531-562.

Pişkin, M., \& Ayas, T. (2011). Akran zorbalığı ölçeği: Çocuk formu. Akademik Bakış: Uluslararası Hakemli Sosyal Bilimler E-Dergisi, 23, 1-12. 
Poteat, V. P., ve Espelage, D. L. (2005). Exploring the relation between bullying and homophobic verbal content: The Homophobic Content Agent Target (HCAT) Scale. Violence and Victims, 20, 513-528.

Salmon, G., ve James, A. (1998). Bullying in school: Self report anxiety, depression and self esteem in secondary school children. British Medical Journal, 317, 63-71.

Satan, A. (2006). İlköğretim ikinci kademe öğrencilerinin zorba davranış eŏilimlerinin okul türü ve bazı sosyo demografik değişkenler ile ilişkisi. İstanbul: Yayımlanmamış Doktora tezi. Marmara Üniversitesi Sosyal Bilimler Enstitüsü.

Schwartz, D., Farver, J., Chang, L., ve Lee-Shin, Y. (2002). Victimization in South Korean children's peer groups. Journal Of Abnormal Child Psychology, 30, 113-115.

Schwatrz, D. (2000). Subtypes of victim and aggressors in children's peer groups. Journal of Abnormal Child Psychology, 28(2), 181-192.

Shujja, S., ve Atta, M. (2011). Translation and validation of 1llinois bullying scale for pakistani children and adolescents. Pakistan Journal of Social and Clinical Psycho$\log y, 9,79-82$.

Tarshis, T. P., ve Huffman, L. C. (2007). Psychometric properties of the Peer Interactions in Primary School (PIPS) questionnaire. Journal of Developmental and Behavioral Pediatrics, 28, 125-132.

Ttofi, M. M., Farrington, D. P., Lösel, F., Crago, R. V., ve Theodorakis, N. (2016). School bullying and drug use later in life: A meta-analytic investigation. School psychology quarterly, 31(1), 8-27.

Uysal, H., ve Dinçer, Ç. (2012). Okul Öncesi Dönemde Akran Zorbalığı. Kuramsal Ĕ̆itimbilim Dergisi, 5(4), 468-483.

Wolke, D., Woods, S., Bloomfield, L., ve Karstsdt, L. (2000). The association between direct and relational bullying and behavior problems among primary school children. Journal Of Child Psychology and Psychiatry, 41, 989-1002.

Yavuzer, Y. (2011). Okullarda saldırganlık/şiddet: Okul ve öğretmenle ilgili risk faktörleri ve önleme stratejileri. Milli Ĕ̆gitim Dergisi, 41(192), 43-61.

\section{Kaynakça Bilgisi / Citation Information}

Aydın, M., Efilti, E. ve Diker, M. (2020). Illinois zorbalık, kavga ve mă̆duriyet ölçeğinin (1zkmö) Türkçeye uyarlama çalışması OPUSUluslararası Toplum Araştırmaları Dergisi, 16(Özel Sayı), 3670-3688. DOI: 10.26466/opus.768247 